\title{
AS REACÕES DOS PROFESSORES DE CIÊNCIAS DIANTE DA IMPLANTAÇẤO DE NOVO CURRÍCULO NA REDE ESTADUAL PAULISTA
}

\author{
Rita de Cássia Bortoletto-Santos* \\ Alice Helena Campos Pierson**
}

RESUMO: A pesquisa realizada,entre 2009e 2013, teve como objetivo investigar como os professores de ciências da rede estadual de ensino de São Paulo reagiram diante da implantação de uma nova proposta curricular para o Ensino Fundamental. Adotou-se uma abordagem qualitativa para o desenvolvimento da pesquisa, utilizando-se de entrevistas semiestruturadas que foram analisadas sob a perspectiva da análise do conteúdo, procurando dar voz aos agentes do currículo, e a partir das ideias de Sacristán, particularmente no que se refere à relação entre o currículo prescrito e as ações dos professores. Neste artigo são apresentadas as reações dos professores diante da nova proposta e analisados seus posicionamentos, sejam eles: favoráveis, desfavoráveis ou pragmáticos.

Palavras-chave: Currículo. Formação de professores.Políticas públicas.

\section{LAS REACCIONES DE LOS PROFESORES DE CIENCIAS A LA IMPLEMENTACIÓN DEL NUEVO CURRICULUM EN LA RED ESTADUAL PAULISTA DE EDUCACIÓN}

RESUMEN:La investigación realizada entre 2009 y 2013 tuvo como objetivo averiguar como los profesores de las ciencias en la red estadual de enseñanza de São Paulo reaccionaron frente a la implantación de una nueva propuesta curricular para la Primaria. Se ha adoptado un abordaje cualitativo para el desarrollo de la investigación, utilizando entrevistas semiestructuradas que fueron analizadas bajo la perspectiva del análisis del contenido, buscando dar voz a los agentes del currículum, y a partir de las ideas de Sacristán, particularmente en lo que se refiere a la relación entre el currículum prescrito y las acciones de los profesores. En este artículo son presentadas las reacciones de los profesores frente a la nueva propuesta y analizados sus posicionamientos, sean: favorables, desfavorables o pragmáticos.

Palabras clave: Currículum. Formación de profesores. Políticaspúblicas.

\author{
* Doutora em Educação pela \\ Universidade Federal de São Carlos \\ (UFSCAR). Educadora I (bolsista da \\ Fundação Universidade de São Paulo \\ (FUSP) no curso semi-presencial de \\ Licenciatura em Ciências e Universi- \\ dade Virtual do Estado de São Paulo \\ UNIVESP). Email: ritabortolettosan- \\ tos@gmail.com \\ * Doutorado em Educação pela \\ Universidade de São Paulo (1997). \\ Atualmente é Professora Associada \\ da Universidade Federal de São \\ Carlos. Email: apierson@ufscar.br
}

DOI - http://dx.doi.org/10.1590/1983-21172015170303 
SCIENCE TEACHER'S REACTIONS TO THE NEW CURRICULUM IMPLEMENTATION IN SÃO PAULO'S STATE PUBLIC SCHOOL SYSTEM

ABSTRACT: This research conducted from 2009 to 2013 aimed to investigate how science teachers of the public school's state system in São Paulo reacted to the implementation of a new curriculum proposal for elementary school. We adopted a qualitative approach in the research development, conducting semi-structured interviews analyzed from the content analysis perspective, trying to give voice to the curriculum's agents, and from Sacristan's ideas, particularly regarding relationship between formal curriculum and teachers' actions. In this article, teachers' reactionstothe new proposal are presented and their positions are analyzed, beingfavorable; unfavorable; orpragmatic.

Keywords: Curriculum.Teacher'seducation.Publicpolicies. 


\section{INTRODUÇÃO}

A implantação de uma nova proposta curricular provoca mudanças na maneira de o professor planejar e conduzir suas aulas, podendo gerar diferentes reações frente às novas demandas. No ano de 2008, a rede de ensino do Estado de São Paulo passou por uma mudança curricular que: assume como princípio educacional o desenvolvimento de habilidades e competências; reorganiza os conteúdos a serem desenvolvidos em sala de aula; e fornece material didático na forma de cadernos para o professor e para os alunos contendo as sequências didáticas a serem desenvolvidas.

Em julho de 2007, a Secretaria de Educação do Estado de São Paulo diagnosticou um desempenho insuficiente de seus estudantes nas provas do SAEB - Sistema de Avaliação da Educação Básica (atualmente Prova Brasil) e do ENEM - Exame Nacional do Ensino Médio, realizadas naquele ano. Tal constatação faz com que o governo estadual elabore dez metas para a Educação Paulista, a serem atingidas até 2010, com o objetivo de melhorar a aprendizagem dos estudantes. Entre essas metas encontram-se: o pagamento de bônus para o magistério estadual, conforme critérios estabelecidos com base no rendimento da escola e na frequência anual dos professores; compra de materiais multimídia e a criação de uma nova proposta curricular, que tem como meta anunciada melhorar a organização do sistema educacional estadual, através da implantação de uma base curricular comum para toda a rede escolar. Tal objetivo surge como uma forma de fazer frente à descentralização resultante da autonomia dada para as escolas, a partir da LDB (Lei de Diretrizes e Bases da Educação Nacional), para a definição de seus projetos pedagógicos.

Dessa forma, ao final de 2007, a Secretaria de Educação organizou o programa São Paulo faz escola. Nos primeiros 42 dias do ano letivo de 2008, todos os estudantes receberam e utilizaram o mesmo material didático (Jornal do aluno) para que fossem executadas as mesmas atividades em todas as salas de aula. Era o início de uma nova organização do trabalho escolar. Tratava-se de uma "recuperação pontual" visando à melhoria do desempenho dos alunos na interpretação de textos e na compreensão de estruturas e operações básicas da matemática.

Naquele momento, todas as disciplinas deveriam trabalhar no sentido de fornecer uma base, recuperando o que era entendido como fundamental para que os alunos pudessem "interagir" melhor com a proposta curricular, que seria efetivamente implantada após aquele período.

Depois dessa primeira etapa, o Caderno do professor tornou-se orientador das aulas a serem ministradas em toda a rede estadual de ensino. Esse caderno é organizado em quatro volumes, um para cada bimestre, contendo sequências didáticas "como sugestão de trabalho" para que o professor desenvolva o conteúdo previsto. Nesse material, constam sugestões de metodologias, de temas, assuntos e maneiras de complementar o conteúdo a ser estudado, com sugestões de tarefa para classe e para casa, além de bibliografia de referência para o professor. Em 2009, chegaram às escolas, além do Caderno do professor, os cadernos dos alunos, divididos em disciplinas e bimestres. Fato que se repete até os dias atuais. 
No caso específico da disciplina de ciências para os anos finais do Ensino Fundamental, os conteúdos estão organizados na proposta em quatro eixos temáticos: Vida e ambiente; Ciência e tecnologia; Serhumano e Saúde; e Terra e universo. A meta principal defendida pela proposta apresentada em 2008 é uma aprendizagem científica que possibilite desenvolver um conhecimento para entender o mundo, para analisar fenômenos naturais e processos tecnológicos, de forma que os alunos possam, a partir dele, posicionarem-se em diferentes situações. Compreender, transformar e agir - estabelecendo relações entre o que já se sabe e o novo (SÃO PAULO, 2008). Deseja-se que os estudantes aprendam a pensar e a expressar seus pensamentos, além de tornarem-se capazes de aplicar o conhecimento construído na solução de problemas cotidianos ou sociais.

Embora o atual currículo tenha inicialmente sido apresentado à rede de ensino pela Secretaria da Educação como uma proposta a ser discutida e aberta a contribuições, desde a etapa inicial a prova anual do Saresp(Sistema de Avaliação do Rendimento Escolar do Estado de São Paulo) já apresentava questões que exploravam os conteúdos sugeridos e buscavam verificar o nível de desenvolvimento, pelos estudantes, das habilidades e das competências previstas na então proposta curricular. O resultado da avaliação é um dos itens que compõem o Idesp (Índice de Desenvolvimento da Educação do Estado de São Paulo), que coloca as escolas da rede estadual num ranking indicador da qualidade de ensino que elas apresentam, sendo os professores bonificados em função do atendimento a metas específicas por escola, definidas pela Secretaria de Educação. Com o passar do tempo, a proposta curricular de 2008foi ganhando novos significados para os diferentes atores envolvidos no processo de sua implantaçãoe, conforme as mudanças foram ocorrendo nas escolas, geraram diferentes reações do corpo docente.

Nesse sentido, o presente artigo tem como objetivo investigar como os professores respondem aos projetos curriculares que chegam à sala de aula, mais especificamente, como o professor de ciências reagiu diante da nova organização curricular para as escolas do Estado de São Paulo, na forma como percebe e organiza seu trabalho docente.

\section{Elementos para uma breve discussão de currículo e do papel do professor no seu desenvolvimento}

Devemos entender o currículo como uma seleção cultural que reflete posicionamentos e compromissos ideológicos de seus propositores. Até o início do século $\mathrm{XX}$, o currículo escolar tinha critérios humanistas e clássicos, com base em obras literárias e artes. Com o desenvolvimento industrial, forças econômicas, políticas e culturais procuravam desenhar a educação de massas, conforme sua própria visão, necessitando um novo modelo de educação e currículo, capaz de desenvolver, nos estudantes, habilidades para a vida profissional adulta que permitissem a eficiência do sistema econômico e político.

O modelo de currículo proposto por Bobbitt (2004) voltado para a eficiência e a economia, numa visão de educação mecânica, mais técnica e menos clássica, se adé- 
qua a essa nova conjuntura. O modelo de currículo escolar proposto tinha por finalidade desenvolver habilidades para o mundo do trabalho adulto, planejando e elaborando instrumentos para medir a eficiência no ensino. Priorizando as formas de organizar e elaborar o currículo, não são questionados os conhecimentos dominantes (SILVA, 2009).

No modelo de currículo tecnicista de Bobbitt (ano??), o professor assume um papel de instrutor, responsável por garantir que seus alunos adquiram as habilidades solicitadas (GESSER, 2002). O professor é um especialista na aplicação de manuais, que dirigem e controlam atividades mecânicas (AZANHA, 2006).

De 1960 a 1970 grupos de movimento dos direitos civis (de mulheres, negros, homossexuais) adquirem um caráter emergente, possibilitando uma discussão sobre currículo e sua reforma com base nas minorias (GESSER, 2002). Para Silva (2009), as transformações sociais e culturais questionavam a estrutura educacional tradicional e, entre os nomes que trazem questionamentos e transformação para o currículo, destacamos neste artigo Bourdieu e Passeron (1975), que na análise e na discussão de sistema de ensino identificam a escola como um aparelho ideológico do Estado.

Sendo a escola um aparelho disseminador de ideologia e um espaço pelo qual praticamente toda a população passa um período prolongado de tempo recebendo informação e formação (reprodução cultural), torna-se um elemento importante na manutenção de determinada organização social. Numa sociedade capitalista, o currículo, ao privilegiar alguns conhecimentos e desvalorizar outros, tem como função manter conceitos culturais de subordinação como naturais, construindo a identidade pessoal que essa sociedade demanda.

A sociedade capitalista depende da reprodução de seus componentes econômicos (força de trabalho e meios de produção) e da reprodução de sua ideologia, através de aparelhos ideológicos do Estado (religião, mídia, familia e escola), apoiados pela força de convencimento de aparelhos de repressão (polícia e judiciário) para manter-se (SILVA, 2009).

O sistema educativo numa sociedade industrial traz mecanismos disciplinadores e serve para atingir níveis mais qualificados, tendo como base o conhecimento tecnológico. Na sociedade da informação e do conhecimento, além de alta qualificação, busca-se a autonomia e a criatividade através da educação. $\mathrm{O}$ indivíduo produzido pelo sistema educativo, nessa sociedade, deve: ser culto, ser bom cidadão, com personalidade adequadamente formada, segundo as orientações sociais, e ser bom trabalhador para garantir a manutenção da produção econômica (SACRISTÁN, 1999).

Resumindo, a política curricular é determinada por confrontos ideológicos e perspectivas econômicas. Os próprios termos utilizados para a política educacional, como prioridade, contratos, projetos, explicam a influência direta de instituições, como o Banco Mundial, envolvendo forças econômicas e sociais (mercado/negociações e governo).

Desse modo, a política curricular explicita a relação de poder (dominação/subordinação), e suas novas reorientações estão pautadas pelas exigências que o mercado impõe para aqueles que nele ingressam, através de suas competências e dos resultados 
em avaliações para cargos ou empregos, numa hierarquia estabelecida pela própria sociedade. Em outras palavras, a escola é concebida como instituição de reprodução, com função social de conservação e ideológica de legitimação, e o currículo permite a reprodução da cultura dominante, que reforça o poder simbólico e a reprodução das relações sociais (BOURDIEU; PASSERON, 1975).

O professor, como autoridade pedagógica, não tem, obrigatoriamente, informações sobre os objetivos implícitos envolvidos em cada ação pedagógica que executa. Nessa perspectiva, ele tem a comunicação que legitima ideias dominantes numa ação de inculcação que, por sua vez, dissemina as relações de poder da sociedade (BOURDIEU; PASSERON 1975). Trata-se da macroinfluência do Estado sobre os professores que atuam no microcontexto da sala de aula (MAINARDES, 2006).

Por outro lado, novas proposições de modelos para a educação envolvem mudanças institucionais e, igualmente, pessoais. Qualquer modelo de escola é traduzido através do currículo e passa pela interpretação e pela ação dos professores para efetivá-lo nas salas de aula. Mudanças no sistema educacional não dependem exclusivamente da coerência de seus planos, mas fundamentalmente do sentido que fazem aos olhos daqueles que estarão diretamente ligados ao processo. Nesse sentido torna-se fundamental considerar o que os professores pensam e fazem, pois são eles que põem, ou não, junto com seus alunos e demais agentes educacionais as novas ideias em prática (THULLER, 2002).

Os professores têm papel fundamental na implantação e na implementação do currículo através de suas ações. Diante das reformas, podem (ou não) perceber o que está por trás delas, podendo criar resistências às novidades ou utilizar-se de suas experiências pessoais, história de vida e contexto social em que estão inseridos. Nesse processo, eles constroem seus saberes que, no caso mais específico do saber relacionado a como dar aulas, vão sendo construídos, fundamentalmente, em atividade. Através das relações com o saber profissional dos professores, podemos buscar explicar algumas reações que estes apresentam diante das orientações de propostas curriculares, que, quando de sua implantação, são novidades para esses e produzirão modificações (ou não) em suas atividades.

Nesse contexto, as ideias de Sacristán (1999, 2000) sobre o currículo, particularmente quanto ao papel do professor como executor das orientações ou seu moldador, trazem a perspectiva de currículo como prática pedagógica que envolve adaptação, resistência e acomodação, conforme o professor interpreta e filtra com sua singularidade o que é proposto.

Esses aspectos nos apontam a existência de: um currículo prescrito em documentos oficiais; um currículo moldado pelos professores nas salas de aula, diante não apenas das condições físicas e humanas reais que eles possuem, mas igualmente da sua compreensão sobre por que, como e o que ensinar; um currículo preestabelecido; e outro consolidado no trabalho dos professores. Essas quatro considerações organizam, em linhas gerais, do ponto de vista teórico, a análise realizada. 


\section{METODOLOGIA}

Procurando conhecer como os professores de ciências reagem diante da implantação de uma mudança curricular que interfere no seu poder de decisão e papel nas salas de aula, buscou-se dar voz a esses professores. Nesse sentido, optamos por uma abordagem qualitativa considerando-a adequada por possibilitar o estudo das questões em seu próprio ambiente, além de valorizar o instrumento humano (ALVES, 1991; LUDKE; ANDRÉ, 1986). A abordagem qualitativa, especificamente voltada para a pesquisa em educação, conforme Ghedin e Franco (2008, p.60), permite ao professor "vir à cena", revelando-se como pessoa, profissional e ser reflexivo, a partir de sua fala, seu olhar e suas experiências. Mostrando-se "como alguém que pensa, decide e se angustia” (GHEDIN; FRANCO, 2008, p. 48), preocupação presente na execução da pesquisa.

Com base nos princípios descritos, procurou-se captar ideias dos sujeitos, utilizando, como instrumentos de coleta de dados, entrevistas semiestruturadas. As entrevistas, pelo fato de aumentarem a flexibilidade para a obtenção de informações, permitem aos sujeitos se expressar melhor do que num questionário e, ao entrevistador, se aprofundar em algumas questões, clareando as informações obtidas.

Oito professoras de ciências formaram o grupo de sujeitos, que teve como critério de seleção a necessidade de ter/estar lecionado ciências nas séries finais do Ensino Fundamental em escolas estaduais, em três momentos: antes de 2008 (experiência docente anterior ao que era proposto), estivessem na sala de aula em 2008 (quando a currículo foi implantado) e no momento da coleta de dados (entrevistas 2010-2011). A idade das professoras variou entre 31 e 54 anos, e o tempo de atuação no magistério ficou entre sete e 26 anos de carreira. Sete delas são efetivas na rede estadual e uma é substituta. Todas têm formação em licenciatura em ciências, sete com bacharelado em biologia, uma com formação, também, em artes e pedagogia. Somente uma formou-se em uma universidade pública, as demais se formaram em instituições particulares. As professoras lecionavam na capital e nas cidades de São Paulo, São Carlos e distrito de Água Vermelha, Sorocaba, Ibaté, Dourado, Descalvado e Américo Brasiliense.

As entrevistas, gravadas e transcritas, foram realizadas de forma a inicialmente conhecermos as professoras entrevistadas, seu percurso profissional e a forma de conceber sua atividade como professora. Buscamos, a partir de seus posicionamentos e relatos de vivência, identificar suas reações quanto à implantação da proposta curricular (de 2008) para a rede estadual paulista. Elas, como autoras da mensagem, escolheram aquilo que imaginavam ser o mais importante com base no seu quadro de referência, em outras palavras, expressam o que têm como concepções, apresentadas e filtradas através do que dizem. 
A análise de conteúdo, associada à análise categorial, mostrou-se apropriada para analisar os dados obtidos, por trabalhar com as palavras, buscando, a partir de sua abrangência, compreender a realidade e construir conhecimento. Trata-se de um estudo mais detalhado das frases, desmontando a estrutura do conteúdo, procurando o sentido, capturando o essencial e descartando o desnecessário, buscando extrair a significação das palavras (LAVILLE; DIONNE, 1999), através de operações de desmembramento do texto em unidades, reagrupados em categorias (BARDIN, 2008). Consiste em um conjunto de técnicas de análise das comunicações que têm como ponto de partida a mensagem (verbal ou escrita) que expressa um significado, carregado de componentes relacionados aos conhecimentos, aos valores e à história de cada indivíduo.

Ao utilizar a análise de conteúdo, o pesquisador assume o papel de detetive, buscando, além do expresso, vestígios e pistas. Começa pela descrição, enumera as características do texto depois de um tratamento inicial. Ao analisar o texto, busca-se produzir inferências, que permitem a interpretação da mensagem (FRANCO, 2005).

Utilizando as quatro etapas da análise de conteúdo propostas por Bardin (2008), primeiramente, o material passou por um processo de pré-análise que, a partir de uma leitura cada vez mais depurada dos textos das entrevistas, vai-se aprofundando e tornando mais precisa a análise realizada, chegando à definição dos trechos a serem mais bem-estudados, selecionados a partir dos objetivos do trabalho. No caso da pesquisa realizada, buscaram-se nos comentários das professoras entrevistadas, diante da proposta curricular de ciências implantada, indícios de resistência ou sua total ausência, ou de adaptações diante do novo projeto de currículo.

Depois dessa seleção, realizou-se um procedimento de exploração do material coletado, procurando interpretá-lo, recortando o texto em unidades, escolhendo os parâmetros de interpretação, segundo o referencial teórico numa dinâmica de codificação (BARDIN, 2008). A partir desse processo, chegamos às unidades de registro que correspondem à menor parte do conteúdo registrada (FRANCO, 2005) e, através delas, aos temas. A opção por temas deu-se por estes permitirem estudar motivações de opiniões, expectativas, atitudes e crenças expressas nos comentários das professoras. Os temas foram determinados a partir da redução das informações contidas nos comentários das professoras entrevistadas.

\section{RESULTADOS}

Após a análise dos dados, foram identificadas três categorias para a análise da relação Professor-proposta, conforme quadro abaixo: 
Quadro 1 - Categorização dos resultados da pesquisa

\begin{tabular}{|l|l|}
\hline TEMA & \multicolumn{1}{c|}{ CATEGORIA } \\
\hline \multirow{3}{*}{ Avaliador de pontos de vista } & $\begin{array}{l}\text { 2. Papel profissional do professor no con- } \\
\text { texto da proposta }\end{array}$ \\
\cline { 2 - 2 } & 3. Posicionamento frente à proposta \\
\hline
\end{tabular}

Fonte: Elaborado pelo autor

Neste artigo discutiremos os aspectos relacionados ao posicionamento do professor frente à proposta, identificada a partir da análise do tema relação professor-proposta ${ }^{1}$.

O currículo escolar, como já mencionado, é produto do contexto histórico em que é desenvolvido, trazendo em suas entrelinhas o modelo de indivíduo que a sociedade pretende formar. O professor é o responsável em transformar as orientações burocráticas e técnicas, apresentadas nos textos oficiais (como as propostas curriculares), em realidade nas salas de aula. Mas o professor, conforme Charlot (2009) menciona, é um ser social e singular ao mesmo tempo, capaz de uma reação individual/singular embasada em sua maneira de ver o mundo, posicionando-se de modo objetivo diante deste. Assim, conhecer como as professoras entrevistadas posicionam-se diante do que foi proposto em 2008, e como veem o que foi vivido efetivamente por elas nas salas de aula, permite apreender como reagiram diante das mudanças.

Sacristán (2000) aponta que o currículo acaba numa prática pedagógica. No caso de uma proposta curricular, antes de tornar-se ação efetiva, passa por processos de adaptação, resistência ou acomodação, entendidos como reações das professoras diante das orientações. Os sentimentos, as percepções e as preocupações que surgiram em seus comentários nos permitem entender como elas se relacionam com o novo currículo.

Dos dados coletados surgiram três aspectos quanto ao posicionamento frente à proposta: (i) contrário face à perda da autonomia; (ii) a favor face à ideia de rede (defesa da unificação de conteúdos e de material) e; (iii) pragmático (indicando um aumento de trabalho e/ou apresentando indícios de adaptação ou acomodação), que passamos, em seguida, a discutir:

\section{(i) Contrário frente à perda da autonomia}

Os cadernos do professor e do aluno e as orientações utilizadas na implantação da proposta curricular de São Paulo de 2008 foram elaborados por especialistas não diretamente ligados às escolas públicas, fora das condi- 
ções práticas diferentes das salas de aulas e escolas. Respeitam os princípios pedagógicos que os orientam, redefinindo conteúdos e procurando trabalhar o desenvolvimento de competências e habilidades numa perspectiva de ensino contextualizado, em consonância comas diretrizes nacionais para a educação. Entretanto, apresentam um direcionamento rígido na definição das atividades a serem realizadas no processo de ensino e uma reorganização de conteúdos pouco discutida com a rede de ensino.Neles o professor perde a possibilidade de planejar livremente suas atividades, além de adquirir uma função de executor ao reproduzir as orientações dadas para a apreensão de determinados conteúdos e desenvolvimento de habilidades pré-determinadas (especificadas em cada situação de aprendizagem proposta). Esses fatores influenciam o pensamento profissional autônomo do professor, reduzindo, ou mesmo tentando eliminar, sua possibilidade de adaptar e transformar, na medida das suas experiências e condições, as orientações e normas que recebe (SACRISTÁN, 2000). Diante dessa predefinição de "o que" e "como ensinar", o processo de implantação dessa proposta curricular foi entendida como uma imposição, conforme sugere o comentário da professora:

Professora P1: [...] eu não gosto de ficar presa aquela... a esse caderno do aluno, ele me entedia muito, eu acho que deveria ser realmente como uma proposta, uma ajuda, (...) assim um livro didático, o material que vem, uma ajuda pro professor, não ele ter que estar seguindo, sabe, porque eu preferia muito mais quando eu usava o livro didático, eu fazia o meu programa, eu não tinha que ficar presa a esse caderno do aluno, mesmo a conteúdos e tudo.

Sacristán (2000) aponta que, através dos livros didáticos, de propostas e guias curriculares ou de avaliações externas, as forças orientadoras e determinantes influenciam nas decisões dos professores. Isso vai ocorrendo de modo cumulativo, gerando diferentes reações como submissão, resistência, adaptação e confronto em diferentes graus e de um modo particular. Desse modo, o professor como profissional traz saberes da experiência, inclusive relacionados às opções metodológicas que faz, que no momento de mudanças curriculares podem se perder ou servirem de apoio para o professor continuar, como aponta outro trecho o comentário da professora:

Professora P1: [...] eu acho que está sendo imposto isso dá [...]. Eu vejo que muitos projetos que eu fazia com a turma, trabalhando, por exemplo, com a questão do lixo tudo, eu vejo sem esse tempo para estar fazendo isso. Eu acabo me preocupando em cumprir aquele conteúdo que está elencando a proposta e acabo não trabalhando com coisas que eu achava relevantes. [...] se eu não faço algumas coisas diferentes daquilo para mim é entediante. 
Outra questão a ser considerada é a da mobilização necessária do professor, como agente executor do currículo. Ao perder sua autonomia, o professor pode não ver sentido naquilo que é sugerido, e reagir com desmotivação, como exemplificado no comentário seguinte:

Professora P2:A parte prática, assim, que eu considero mais prática, que chama a atenção, que ajuda a entender, eu perdi. Eu sinto que eu perdi muito com a proposta nova, porque ficou muito conteúdo.[...]Eu não gostei. Achei muito extensa, muito detalhada nos tópicos, mas muito superficial. Você não tem tempo para desenvolver. [...] Esse negócio que todos os temas têm que ser vistos, em todas as séries, eu acho que não funciona, fica cansativo para todos, especialmente para o professor. Sinto-me esgotada, física e mentalmente.

A proposta curricular ofereceu aos professores uma nova organização de conteúdos, estabelecendo o tempo para que ela fosse desenvolvida, os materiais que deveriam ser utilizados e a maneira de avaliar se as competências e as habilidades esperadas foram efetivamente desenvolvidas.

Analisando as colocações apresentadas aqui, podemos identificar aspectos apontados por Sacristán (1999) no sentido em que o professor controla suas ações e relações diante da proposta curricular que lhe foi apresentada como uma nova situação, ele sabe o que está acontecendo e o que está fazendo. Isso pode gerar reflexões, quanto ao "por que fazer" e "como fazer". Nesse sentido, temos algumas professoras que procuram, mesmo reconhecendo a perda de autonomia, retomá-la, ainda que em parte:

Professora P3:A princípio eu me senti meio amarrada, porque tudo que é imposto, porque não foi feito um estudo com todos os professores, ou sei lá, um grupo de professores que achou que a proposta deveria ser posta dessa forma que foi. Então quando você já vem de um tempo muito grande de trabalho, você tem algumas coisas, que quando você faz você já se satisfaz em aplicar aquilo que você fez. [...]. Com o passar do tempo é que eu percebi que eu poderia juntar as duas coisas, porque só no uso da proposta te faz mal, porque você perde a sua liberdade de atuação, você fica muito vinculada ao tempo.

\section{(ii) Favorável face à ideia de rede}

Outro aspecto que surgiu nos comentários das professoras, incluídos na categoria referente ao seu posicionamento diante da proposta, trata da sua defesa por perceberem que através dela as escolas estaduais paulistas podem funcionar efetivamente como uma rede. Essa defesa ocorre por diferentes razões, entre elas destaca-se a unificação de conteúdos e material, além de fornecer um caminho para a avaliação do Saresp.

A professora entrevistada P3 mostra uma percepção de que o currículo se relaciona ao momento histórico em que a sociedade está inserida e defende a necessidade de mudança: 
Professora P3:Primeiro, historicamente o currículo sempre muda por uma necessidade política e econômica que um país atravessa. Nosso país estava necessitando dessa mudança. Eu me coloco a favor quanto a sua unificação e me posiciono contra quanto a sua aplicação. [...] Eu acho importante unificar todo o currículo, inclusive eu fiz um curso sobre a história do currículo. Então dentro da história a gente vem mudando muito o currículo em decorrência das necessidades atuais. Agora não é diferente, porque a gente está precisando de mão de obra e ainda continua voltada para isso, você tem que ter um ensino rápido, para ter mão de obra rápida, mas está unificado.

Mesmo parecendo bastante convicta em sua defesa, defendendo a proposta como orientadora do que se ensinar, posiciona-se contrária à forma como se deu sua aplicação. Mesmo partindo de outra compreensão de currículo, o incômodo gerado pela maneira como a proposta foi implementada pode ser identificado a partir do comentário de outra professora entrevistada: Professora P1: "Olha, a mudança foi para unificar, unificar conteúdo, mas eu acho que isso poderia ser feito de outra forma, tudo bem unificar conteúdo, porque a gente pegava aluno, mesmo dentro da própria escola, com conteúdos diferentes $[\ldots] "$.

$\mathrm{Na}$ fala de outras professoras, reconhecemos posicionamentos positivos frente à definição de um currículo único pensando nos processos de transferência de alunos. Outro fator que levou à defesa do novo currículo foi a distribuição do material na forma de caderno:

Professora P3:Também, ajuda porque esses caderninhos, porque você tem o material ali. Antes eu tinha que pegar do meu dinheiro, tirar xerox de alguns textos que eu acho importante da gente trabalhar. [...] Agora quando tem o caderninho para todo mundo, você consegue trabalhar ao mesmo tempo todo mundo[...]. Você pode cobrar aquilo como avaliação.

Como a escola pública recebe alunos de diferentes situações econômicas, a unificação e a disponibilidade de material didático individual para cada estudante pelo menos sugere uma colaboração no sentido de garantir um mínimo de possibilidades de aprendizagem para todos.

A defesa da proposta, quanto à unificação do currículo, principalmente na organização de conteúdos, passa pela ideia de que dessa forma se deu uma direção a ser seguida pelas professoras, ampliando, inclusive, seu conhecimento conforme realizavam pesquisas para suas aulas.

Professora P7:Eu acho que a proposta nova do Estado foi boa porque deu um norte. Todo mundo, queira ou não, trabalha a mesma coisa. [...] na verdade, a proposta nossa é um norte, porque daí tem os livros didáticos dos alunos que não têm o assunto, a gente pesquisa em outro lugar, muita pesquisa na internet. [...] Agora existem outros colegas que têm dificuldades, que não gostam da proposta, que não seguem, quer dizer, depende da visão de cada um. 
Professora P5:[...] a escola pública hoje tem um eixo para seguir. É de acordo com a proposta. E a proposta está ali, você pode utilizar ela, mas não tem como seguir só ela. [...] Então nesse sentido para mim ficou mais fácil, porque não que eu não continue procurando, mas eu tinha um eixo para seguir.

Esse fator de direcionamento diminui ainda a ansiedade quanto aos conteúdos que serão avaliados no Saresp através de questões de múltipla escolha:

Professora P5:Foi como eu falei, para mim eu vi com bons olhos tudo aquilo, por conta disso, era uma coisa que me causava agonia aquela mistura. Depois chegava no Saresp, teve Saresp de ciências, você sabia o que realmente ia se cobrar naquele Saresp [...]. Para mim eu achei muito bom.

Professora P4:Eu acho que, de repente, é uma forma de avaliar. Eles vão usar isso, pelo menos é o que a gente espera, que eles usem no caso do Saresp, o conteúdo disso nas avaliações externas. Eu acho que eles querem isso, avaliar para ver como está.

Em síntese, pode-se perceber que a unificação do currículo, em termos de organização de conteúdos, foi bem aceita pelas entrevistadas, que indicaram a possibilidade de todos os alunos estudarem os mesmos assuntos, na mesma série, diminuindo possíveis defasagens de conteúdo quando ocorrem transferências entre escolas estaduais. Esse era um dos objetivos que a Secretaria de Educação Paulista colocou quando da implantação da proposta curricular de 2008. A preocupação em trabalhar assuntos relacionados ao Saresp indica uma preocupação com a cobrança do sistema, que pretende avaliar "para ver como está". Indicativo de um controle do Estado sobre a ação do professor. Embora as professoras tenham um posicionamento de defesa da implantação da proposta curricular, elas mostram-se preocupadas com a cobrança de resultados. Esse aspecto aparece, por exemplo, nos comentários referentes ao controle da equipe gestora (coordenação ou direção), que procurava identificar, através de registros escritos, se os conteúdos estavam sendo cumpridos pelos professores, como relata a professora entrevistada P4 (que faz referência à diretora da escola): "Professora P4: Além do diário, a gente tinha que fazer umas coisas, umas fichas que a gente tinha que preencher com o que a gente tinha que dar, tinha que passar por ela”.

Embora não utilize diretamente registros burocráticos, o controle pode vir de outra maneira, por exemplo, através do relato dos alunos:

Professora P5:Lá na minha escola tem duas coordenadoras, a do Fundamental e a do Médio. A do Médio é sempre quem faz mais, a do Fundamental é mais sossegada. Então o que elas fazem, de tempos e tempos, elas pegam os dois representantes, não na minha disciplina, em todas. [...] pedem o caderno e todas as apostilas e perguntam professor por professor: quem está seguindo, quem não está, como é a aula deste, como é a aula daquele. 
Os sinais de um controle continuam de modo mais discreto como a fala da professora abaixo sugere: Professora P3: “[...] eles te dão liberdade, não precisa ficar amarrado no caderninho, mas na hora de eles colocarem o Saresp, eles colocam em cima do caderninho".

Nos três comentários acima, percebe-se o papel controlador do Estado, seja através de superiores imediatos das professoras (equipe gestora), seja por meio da cobrança dos conteúdos no próprio Saresp.

A partir dos comentários das professoras entrevistadas, pôde-se perceber que, apesar da defesa da proposta curricular como uma proposta capaz de levar as escolas estaduais a funcionarem como uma rede, ela gera, para alguns, preocupações, no que se refere a cumprir os conteúdos propostos para um bom desempenho dos alunos no Saresp.

Diante desse fato, lembrar o modelo de currículo proposto por Bobbitt (ano??) parece oportuno. Não pela ideia de organizar um currículo, visando a uma formação para a vida adulta produtiva, mas pela ideia de o processo de aprendizagem não poder ser comparado a um processo industrial. Trata-se de padrões predeterminados nas avaliações externas, a partir de um currículo único, que propõe, além da organização de conteúdos, a construção de habilidades e competências. Porém, cada indivíduo é singular, constrói-se a si mesmo a partir das experiências que viveu e da visão de mundo que possui. A segunda questão remete-nos às ideias de Bourdieu (1975), ao poder simbólico exercido pelo Estado através do currículo. Esse currículo foi construído por especialistas, sem a participação dos professores, e expressa relações de poder de alguns grupos. Esses, por sua vez, são agentes operativos do currículo, tornando, ou não, realidade nas salas de aula aquilo que foi idealizado nos gabinetes. Na relação que estabelecem com a proposta curricular, aparece no comentário de várias professoras a preocupação com os resultados obtidos, não na perspectiva de este ser um indicativo da aprendizagem do aluno, mas como um indicativo de uma percepção do sistema como agente controlador.

\section{(iii) Postura pragmática}

Outra perspectiva identificada pela pesquisa envolve uma relação mais pragmática do professor com a proposta, expressa nos comentários de algumas entrevistadas. Identificamos um posicionamento pragmático quando, diante da situação que vivem ou viveram, fornecem uma avaliação mais direta, como, por exemplo, a nova proposta curricular ter trazido um aumento de trabalho. A posição que expressam não é em defesa ou contra a proposta, são comentários que não trazem em si uma análise mais crítica do projeto, mas, essencialmente, uma posição bastante objetiva diante da situação apresentada, que estamos aqui identificando como pragmática.

Um comentário nesse contexto refere-se à organização do conteúdo nos cadernos do aluno, que apresentam um tema considerando que os estudantes já possuem os pré-requisitos necessários para sua abordagem: 
Professora P6: [...] está muito jogado. É aquilo que eu te falei, eles tacam um tema ali, o exemplo da oitava série, eles não sabem o que é uma onda eletromagnética. Já vem: as ondas eletromagnéticas no seu dia a dia. Ele tem no dia a dia, mas ele não sabe. [...] Então, a maneira que está colocada ali, é justamente essa, que o aluno vá em busca de conquistar, de aprender. E acaba que sobrecarrega o professor, que ele não vai. Se eu quero fazer, eu tenho que eu ir atrás, ajudar em uma parte.

Um dos objetivos da proposta curricular é tornar o aluno capaz de aprender a levantar informações em diferentes fontes (escritas, eletrônicas). Isso implica uma procura de informações também pelo professor, conforme o comentário da professora:

Professora P7: [...] porque a gente trabalhava muito pouco com pesquisa. Hoje, a proposta obriga a se trabalhar muito mais com pesquisa. Aí faz o professor ficar antenado, porque quando você pede para pesquisar um assunto, você não pode ficar leigo, você tem que pesquisar também, porque o aluno vai te perguntar.

Esse fato sugere ao professor que o livro didático não é mais o único material a ser utilizado na preparação de suas aulas, conforme o comentário da professora entrevistada P4: "Olha! Mudou o seguinte, a gente tinha o livro e gente seguia o livro, então não tinha muito aquela preocupação de você preparar a coisa. Agora não, você tem que correr atrás, que preparar, porque se não você não dá aula".

Em outro trecho de sua fala, a mesma professora coloca

Professora P4:Ela complicou porque misturou muito o conteúdo, como eu falei bagunçado, misturou muito. Aí, o jeito que a gente dá é aquela coisa: se corre atrás, se prepara texto, se prepara material, tudo para trazer para eles, para não ter que sair de uma oitava série emprestando livros de uma sétima, saindo de uma sétima emprestando livro de uma quinta, evitar [...] essa caminhada dentro da escola, então eu preparo em casa. O jeito que eu dei é preparar as coisas e trazer para eles.

A visão de “mistura", citada pela professora, ocorre em virtude da nova organização dos conteúdos a partir de quatro eixos temáticos já citados anteriormente (Vida e ambiente, Ciência e tecnologia, Serhumano e saúde, e Terra e universo) que são retomados nas diferentes séries, buscando desenvolver habilidades e competências de acordo com a faixa etária dos estudantes. Com a nova organização curricular, o professor não tem mais o livro didático como único meio de consulta e orientador das aulas. Esse fato aparece no comentário de outra professora entrevistada

Professora P7:Pesquisava no livro didático. Porque você usava o livro didático e ele trazia tudo para você. Certo? Agora não, a proposta traz o assunto e um texto. Você não pode só pensar nisso. Você tem que ler, porque você tem que falar para o aluno, você tem que inserir o conhecimento nele, através do que, tem que pesquisar muito mais. 
Essa mudança modifica o trabalho do professor, que deve buscar materiais e fontes diferentes para compor suas aulas. Temos aqui dois aspectos a serem considerados: a mudança na organização do currículo e o uso do livro didático, fatores de acomodação do professor, que já tinha o esquema anterior em mente: $6^{\circ}$ ano: água, ar, solo; $7^{\circ}$ ano: seres vivos; $8^{\circ}$ ano: corpo humano; e $9^{\circ}$ ano: noções de química e física.

Há, ainda, exemplificando o que identificamos como uma postura pragmática, os comentários das entrevistadas que nos remetem a uma adaptação e/ou acomodação diante das orientações dadas pela proposta de 2008. Entende-se adaptação como a aceitação à medida que se faz algo. Essa ideia pode ser ilustrada pelo seguinte comentário:

Professora P7:No primeiro momento a gente tem um pouco de receio, mas só que todo ser humano, ele reage àquilo que é novo. [...] só que a gente [...] não pode não gostar daquilo que você não conhece. Primeiro você tem que trabalhar para ver, por exemplo, tem muita coisa que dá para você adaptar. [...] A gente fica meio perdida [...] o que vai ser? O que vai cobrar? Como vai ser? Como eu vou cobrar? Daí você vai, conforme você vai trabalhando, você vai achando o caminho, vai se adequando, vai ficando cada vez melhor.

Conforme a proposta curricular é implantada, há uma perda da autonomia identificada pelas professoras, e esse fato causa-lhes sentimentos desconfortáveis e,por vezes, desmotivadores. Mas, para além deles, é possível ocorrer um diálogo entre a prática já incorporada pelas professoras e as sugestões dadas pela Secretaria da Educação, sugerindo uma adaptação, conforme podemos observar no comentário da professora entrevistada:

Professora P3: Com o passar do tempo é que eu percebi que eu poderia juntar as duas coisas, porque só no uso da proposta te faz mal, porque você perde a sua liberdade de atuação, você fica muito vinculada ao tempo. Você tem que fazer aquelas atividades que você tem que terminar, que você tem que trabalhar, e que aquilo é tudo em função do Idespe [...] você não acaba tendo a felicidade de trabalhar com liberdade. A partir do momento que eu consegui me desvincular dessas amarras, que eu consegui perceber que eu posso fazer as duas coisas, é que eu passei a me sentir melhor, mas a princípio eu tive desagrado em trabalhar. Então mudou nesse sentido, de (eu) adaptar algumas coisas que veio dentro da proposta, em termos de exercícios para aplicação e daquilo que eu já fazia antes.

A organização dos conteúdos foi um dos fatores que mais provocaram adaptações na prática das professoras:

Professora P7: Quando a proposta veio, a gente fica [...] meio ressabiado de como fazer, de como não fazer, agora de 2008 para 2011, você já teve um tempo, conhece muito melhor o material. Eu acho que a cada ano você consegue melhorar mais. [...] Estou mais tranquila, nossa muito mais. [...] Organização de conteúdos a gente estranha um pouco, porque o que a gente dava no primeiro bimestre, está lá no terceiro,mas agora já acostumou. 
Conforme as atividades vão sendo executadas nas salas de aula, as professoras passam a se acostumar com o que é sugerido, principalmente, no que se refere à nova organização dos conteúdos. A adaptação passa pelo fazer e,à medida que vai acontecendo, modifica sentimentos e reações, conforme expressa o comentário abaixo:

Professora P6: Tranquilidade, assim, não. Eu falaria, mais uma mudança: como fazer? E tudo é novo e diante do novo você se assusta. [...] eu fui testando, o que dava mais certo. [...] Se você me perguntasse quando ela foi implantada, eu ia dizer horrível, péssima. Agora hoje eu já me acostumei.

Considera-se a acomodação, como acostumar-se a fazer. Isso ocorre pela própria aceitação do que foi proposto. Pode-se perceber igualmente acomodação no comentário de outra professora entrevistada:

Professora P2: [...] eu sigo fielmente. Eu estou seguindo a proposta, mesmo porque na escola tem uma cobrança muito grande de a gente seguir a proposta. [...] Eu sigo do jeito que está lá. Mesmo porque a coordenadora, cobra da gente que qualquer coisa que tenha que ser mudada, nósteremos que justificar.

Nesse caso, a acomodação parece ocorrer pela cobrança que é imposta na escola, tornando mais trabalhoso realizar alguma mudança e ter que justificá-la para superiores.

Pode-se dizer que na acomodação pode haver uma resistência. No caso a resistência ao novo, à mudança. É menos trabalhoso aceitar aquilo que foi imposto.

A professora entrevistada P8 aponta uma reação negativa diante da necessidade de mudar algo que vinha fazendo, mas ao mesmo tempo declara estar pronta às mudanças, mais um indicativo de adaptação:

Professora P8: Olha, é inerente ao ser humano ele ficar meio bloqueado, revoltado, quando ele é obrigado a mudar uma coisa, que já está há muito tempo, ali na sua rotina. Então, [...] no planejamento veio essa notícia, que ia ter caderno do aluno, que ia ter isso, que ia ter aquilo. [...] Então trabalhamos com os jornais primeiro, antes de trabalhar com os cadernos. Eu gostei de trabalhar com aquele jornal. Eu sou uma pessoa muito aberta a mudanças. Você entendeu? Eu trabalhei numa boa, trabalho até hoje numa boa.

O comentário da professora faz referência a uma resistência que identifica como própria do ser humano em relação ao novo, mas que, depois de passado o processo inicial da implantação da proposta curricular, parece desaparecer. Expressa uma ideia positiva de adaptação às mudanças. Ao refletir sobre a fala da professora, parece-nos preocupante assumir-se como parte de um processo natural a resistência inicial a mudanças e a adaptação ao novo como algo que deva ocorrer independente das razões e dos objetivos que jus- 
tificam mudar. A aceitação pelo professor do papel de executor de propostas organizadas por especialistas não é, entretanto, consenso entre as professoras entrevistadas, mesmo quando estas a aceitam e reconhecem que podem trazer contribuições:

\begin{abstract}
Professora P5: Então, os caderninhos eu gosto, só que é o que eu falei, eu acho falho porque não tem uma atualização.[...] Eles elaboraram essa proposta, mas tem que de tempos em tempos, eles sentarem com pessoas que desenvolvem isso, e falar o que vocês acham, o que deu certo e o que não deu e o que nós podemos tentar mudar. Não é que eu acho que a apostila tem que chegar para mim pronta, eu sou educadora, eu concordo, eu tenho que buscar outras estratégias, mas tem que haver uma análise crítica do que está dando certo e do que não dá.
\end{abstract}

Neste último comentário, a professora chama a atenção para a necessidade de os responsáveis pela implantação curricular ouvirem aqueles que realmente a executam na sala de aula: os professores. Acompanhando as ideias de Sacristán(2000), não se deve desprezar a capacidade crítica, reflexiva e criativa dos professores, que, entre outros espaços, têm nas salas de aula um local importante de construção de novas estratégias e saberes. Ninguém melhor do que eles próprios para apontar sucessos e falhas (com possíveis correções) naquilo que é proposto nocurrículo. Os professores devem ser considerados agentes ativos na implantação e na execução de propostas curriculares, por interpretarem de modo pessoal o currículo, realizarem adaptações conforme as necessidades de seus alunos e condições de trabalho (SACRISTÁN, 2000).

Encerrando a análise dessa categoria, podemos inferir, a partir desse último comentário e de outros apresentados anteriormente, que a proposta curricular paulista foi introduzida na rede de ensino a partir de um modelo intervencionista e burocrático, que busca fazer do professor um executor, ignorando que os professores têm um pensamento profissional próprio, que vai além das condições de seu trabalho e que ao retirar dele a autonomia e uma participação ativa, corre-se o risco de haver um posicionamento de acomodação, com a justificativa de cumprir o estabelecido sem ter que explicar as próprias decisões.

\title{
Considerações finais
}

A análise do posicionamento das professoras frente à proposta levou-nos a comentários a favor, frente à ideia de as escolas estaduais atuarem como uma rede, tanto em termos da unificação dos conteúdos, como na possibilidade de um melhor desempenho das escolas no Saresp. Outras apresentaram um posicionamento mais pragmático expressando, nos seus comentários, uma análise numa perspectiva mais individual, a sua visão a partir do seu trabalho, sem fazer referência ao processo de maneira mais global. A adaptação ao que 
é proposto revela uma posição de acomodação, mesmo surgindo comentários referentes à profundidade e ao tempo para desenvolver os conteúdos, as professoras fizeram adaptações com base naquilo que conheciam. Esse posicionamento mais pragmático tem maior ressonância com uma visão do papel do professor como executor da proposta curricular, implementador de um currículo elaborado por especialistas, dado que não questiona a possibilidade de participação no processo de sua elaboração nem sua posição de concordância ou não com os novos objetivos colocados para a Educação Básica.

Um posicionamento contrário à proposta curricular, que aparece nos comentários das professoras, é atribuído à sua perda da autonomia, à liberdade de escolha dos conteúdos a serem trabalhados, que deixa de existir com o novo currículo.

Por outro lado, é interessante observarmos que, mesmo as escolas tendo que produzir seus Projetos Políticos Pedagógicos, toda vez que os comentários das professoras fazem referência à perda de autonomia, essa se refere exclusivamente à autonomia do professor e nunca à autonomia da escola, às metas propostas no seu projeto pedagógico. Tal fato pode ser um elemento explicitador de um caráter bastante solitário do trabalho do professor. É interessante observamos que, durante nossas entrevistas, praticamente não há referência a conversas ou discussões, nas escolas, sobre como ensinar algo, como eventualmente adequar atividades à realidade da escola ou mesmo compartilhar os incômodos gerados pela nova proposta. Tais comentários, quando aparecem, são bastante superficiais e, aparentemente, não resultam em compartilhamento de experiências.

A discussão dos objetivos da proposta, a busca por desenvolver habilidades e competências e a distribuição dos conteúdos em eixos temáticos, aspectos estruturantes da proposta, não aparecem nos comentários das professoras.

A partir desses dados, considera-se que o professor, embora defenda ou faça o que está na proposta curricular, mantém ideias próprias, construídas a partir de sua experiência, não demonstrando terem se apropriado das ideias daqueles que a elaboraram, seja para concordar ou discordar dessas.

Podemos entender que a mobilização necessária para uma efetiva implantação da proposta não ocorre e, se os quisermos como aliados no processo de implementação, o que foi proposto deveria fazer sentido. Este fato pode explicar as suas ações e reações. Desprezou-se a capacidade crítica e criativa dos professores, a preocupação fica na possibilidade de eles "aprenderem a fazer" conforme o prescrito. Ignora-se o seu "saber ensinar" (SACRISTÁN, 1999) e sua capacidade em discutir o ensino de ciências numa perspectiva crítica, seu papel como um sujeito com ideais, valores e distintas compreensões do seu papel social.

As relações de poder do Estado estão na base da elaboração da proposta curricular. Entretanto, mesmo os comentários das professoras não de- 
monstrando essa percepção, quanto à escolha e organização dos conteúdos, eles sugerem uma resistência à nova organização embasada no conhecimento que elas construíram a partir do "seu fazer" e do "saber sobre o fazer" (SACRISTÁN, 2000). Toda a orientação curricular acaba numa ação prática pedagógica que, dependendo do que o professor, como indivíduo, construiu, pode ser de adaptação, resistência ou acomodação.

A proposta curricular é um instrumento político que, por meio de um documento oficial, expressa intenções, mas é nas salas de aula que ela se torna real, mostrando-se como a face que se usa, aquilo que os professores fazem na prática que, como vimos, pode estar distante do que foi idealizado. Os professores interpretam os textos políticos a partir de suas visões, posições políticas e os adaptam à sua prática, como seres singulares que são, transformando, conforme Sacristán (2000) afirma, o currículo prescrito em currículo moldado.

Por não estarem incluídos no processo de elaboração da proposta curricular, os professores tendem à acomodação e ao conformismo diante do texto oficial, incorporando a orientação ao seu trabalho diário, mas sem realmente concordar ou acreditar naquilo. É um posicionamento a ser considerado, se entendermos que o professor deve promover o desejo de aprender em seus alunos, mas ele mesmo, como agente meramente executor de um projeto que não é o seu, não se mostra entusiasmado com aquilo que faz. Tal fato acaba levando para um horizonte quase inatingível, pois um dos maiores desafios que a proposta curricular coloca para o professor está em fazer seus alunos desejarem aprender, já que o foco da atividade escolar é a aprendizagem do aluno. Como fazer isso se ele próprio se vê desmobilizado para realizar tal tarefa?

Sem dúvida, a proposta curricular pretende desenvolver uma relação de poder ao tentar regular o trabalho do professor, inclusive em aspectos que anteriormente ele tinha autonomia (organização de conteúdos, propostas de objetivos, metodologias de aula, uso de recursos didáticos e formas de avaliação). Ao desconsiderarmos o que Sacristán (1999) chamou de "singularidade do eu", no nosso caso do professor, corre-se o risco de empobrecer as propostas educacionais. O professor é o agente do currículo, responsável pela passagem do currículo prescrito para o currículo em ação, num processo decisivo e intencional. Quando o professor é colocado à margem da elaboração de orientações com as quais vai trabalhar diretamente, ele precisa enxergar nelas um sentido, uma vontade para realizar. Não se pode descartar a cultura profissional do professor, capaz de desencadear ações que respeitem as especificidades dos estudantes e da regionalidade de cada escola.

\section{NOTAS}

${ }^{1} \mathrm{~A}$ análise das demais categorias pode ser encontrada na tese de Bortoletto-Santos (2008). 


\section{REFERÊNCIAS}

AZANHA, J.M.P. A formação do professor e outros escritos.São Paulo: Senac, 2006.

ALVES, A. J. O planejamento da pesquisa qualitativa em educação. Caderno de Pesquisa, São Paulo, n. 71, p. 53-63, 1991.

BARDIN, L. Análise de conteúdo. Lisboa: Edições 70, LDA, 2008.

BOBBITT, John Franklin. O Currículo. Porto: Didáctica Editora, 2004. 268 p.

BOURDIEU, P; PASSERON, J. C. A reprodução. Elementos para uma teoria do sistema de ensino. Rio de Janeiro: Francisco Alves, 1975.

CHARLOT, B. A escola e o trabalho dos alunos. SÍSIFO/Revista de Ciências da Educação, local de publicação??, n. 10, p. 89-96, 2009. Disponível em:<http://sisifo.fpce.ul.pt>. Acesso em: 20 fev. 2012.

FRANCO, M. L.P.B. Análise de conteúdo. Brasília: Liber Livro, 2005.

GESSER, V. A evolução histórica do currículo: dos primórdios à atualidade. Contrapontos, Itajaí, Ano 2, n.4, p. 69-81, 2002

GHEDIN, E.; FRANCO, M.A.S. Questões de método na construção da pesquisa em educação. São Paulo: Cortez, 2008.

LAVILLE, C.;DIONNE, J.A construção do saber: manual de metodologia da pesquisa em ciências humanas. Porto Alegre: Artmed, 1999.

LUDKE, M.; ANDRÉ, M.E.D.A. A pesquisa em educação: abordagem qualitativa. São Paulo: EPU, 1986. MAINARDES, J. Abordagem do ciclo de políticas: uma contribuição para a análise de políticas educacionais. Educação e Sociedade. Campinas, v. 27, n.94, p. 47-69, 2006.

SACRISTÁN, J.L. Poderes instáveis em educaşão. Porto Alegre: Artes Médicas Sul, 1999.

SACRISTÁN, J.L. O currículo: uma reflexão sobre a prática. Porto Alegre: Artmed, 2000.

SÃO PAULO (Estado) Secretaria de Educação. Proposta curricular do Estado de São Paulo (Geral). São Paulo, SEE, 2008. Disponível em: <http://www.rededosa

ber.sp.gov.br/portais/Portals/18/arquivos/PropostaCurricularGeral_Internet_md.pdf > . Acesso em: 20 fev.2012.

SILVA, T.T. Documentos de identidade: Uma introdução às teorias do currículo. Belo Horizonte:Autêntica,2009.

THULLER, M. G. O desenvolvimento profissional dos professores: novos paradigmas, novas práticas. In: PERRENOUD, P. et al. A formação dos professores no século XXI. Porto Alegre: Artmed, 2002. p.89-111.

\section{Data da submissão: 15/02/2015 \\ Data de aprovação: 03/08/2015 \\ Data Versão Final: 03/09/2015 \\ Contato: \\ Rita de Cássia Bortoletto-Santos}

Av. Carmem aparecida Garcia, 61 - Parque Fehr - São Carlos, SP - Brasil

Cep: 013563-776 